\title{
Delayed IGF-1 Administration Rescues Oligodendrocyte Progenitors from Glutamate-Induced Cell Death and Hypoxic-Ischemic Brain Damage
}

\author{
Teresa L. Wood ${ }^{\mathrm{a}, \mathrm{b}}$ Vaho Loladze ${ }^{\mathrm{b}}$ Stefanie Altieri ${ }^{\mathrm{a}} \quad$ Nitish Gangoli $^{\mathrm{a}}$ \\ Steven W. Levison ${ }^{a}$ Katarina G. Brywe ${ }^{c, d}$ Carina Mallard ${ }^{c}$ Henrik Hagberg ${ }^{c, d}$ \\ a Department of Neurology and Neuroscience, New Jersey Medical School, University of Medicine and Dentistry \\ New Jersey, Newark, N.J., ' ${ }^{b}$ Department of Neural and Behavioral Sciences, Penn State College of Medicine, \\ Hershey, Pa., USA; Departments of ${ }^{\mathrm{C}}$ Neuroscience and Physiology, and ${ }^{\mathrm{d}}$ Obstetrics and Gynecology, \\ Sahlgrenska Academy, Gothenburg, Sweden
}

\section{Key Words}

Insulin-like growth factor $\cdot$ Trophic factors $\cdot$ Periventricular leukomalacia - White matter damage $\cdot$ Excitotoxicity $\cdot$

Apoptosis $\cdot$ Myelin

\begin{abstract}
We previously demonstrated that IGF-1 blocks glutamatemediated death of late oligodendrocyte progenitors (OPs) by preventing Bax translocation, mitochondrial cytochrome c release and cleavage of caspases 9 and 3 . Here, we demonstrate that IGF-1 prevents caspase 3 activation in late OPs when administered up to $16 \mathrm{~h}$ following exposure to glutamate. Moreover, late addition of IGF-1 to OPs previously exposed to toxic levels of glutamate promotes oligodendrocyte maturation as measured by myelin basic protein expression. We also demonstrate that intraventricularly administered IGF-1 retains OPs in the perinatal white matter after hypoxia-ischemia when given after insult. These results suggest that delayed administration of IGF-1 will rescue OPs in the immature white matter and promote myelination following hypoxia-ischemia.

Copyright $\odot 2007$ S. Karger AG, Basel
\end{abstract}

\section{Introduction}

White matter damage occurs after ischemia in both the adult and the immature brain. However, in contrast to adult stroke where the predominant pathology is neuronal cell death, many of the neurological problems of the infant subsequent to hypoxia-ischemia (HI) are attributed to white matter damage [Volpe, 2001a, b]. White matter damage in perinatal HI leads to periventricular leukomalacia, which is the neuropathology classically associated with brain injuries in the premature infant [Volpe, 2001a]. As in the adult, glutamate is elevated in the immature rat brain including in the white matter after HI and is thought to have a primary role in the subsequent damage [Benveniste et al., 1984; Hagberg et al., 1987; Andine et al., 1991; Silverstein et al., 1991]. Similarly, glutamate is elevated in the cerebral spinal fluid in term infants after perinatal HI [Hagberg et al., 1993]. Recently, Back et al. [2007] demonstrated that HI causes release of glutamate preferentially from axons and oligodendroglia in the perinatal brain. Multiple lines of evidence support the hypothesis that the AMPA/kainate GluR receptors are primarily responsible for glutamate-mediated death of oligodendrocyte progenitors (OPs) and immature oligodendrocytes both in vitro [Yoshioka et al., 1995; Mat-

Teresa L. Wood, PhD

Department of Neurology and Neuroscience, New Jersey Medical School/UMDNJ UH-Cancer Center H1200, 205 South Orange Avenue

Newark, NJ 07103 (USA)

Tel. +1973972 6529, Fax +1973972 0008, E-Mail woodte@umdnj.edu 
ute et al., 1997; Sanchez-Gomez and Matute 1999; Alberdi et al., 2002] and in vivo [Follett et al., 2000].

The differential vulnerability of oligodendroglia as they progressively differentiate has led to the view that the immature progenitors are significantly more vulnerable than mature oligodendrocytes. In particular, the late progenitor (late OP) is the most sensitive developmental stage to kainate- and glutamate-mediated death [McDonald et al., 1998b; Fern and Moller, 2000] and to oxidative stress induced by glutathione depletion [Back et al., 1998]. Follett et al. [2000] reported a similar age-dependent vulnerability to white matter lesions after intracerebral injections of AMPA into the pericallosal white matter. These data have led to the proposal that the late OP is intrinsically vulnerable to hypoxic/ischemic insult [Volpe, 1997]. Indeed, the age of highest incidence of white matter damage leading to periventricular leukomalacia in the premature infant directly correlates with the predominance of late OPs in the immature brain [Back et al., 2001; Riddle et al., 2006].

In contrast to the classic NMDA-mediated excitotoxic death of neurons that occurs within a few hours, death of oligodendroglia after $\mathrm{HI}$ in the perinatal brain occurs over 24-48 h [Follett et al., 2000; Ness et al., 2001]. This suggests that the initial elevation of glutamate initiates a slow death cascade within the glial cells. Until recently, little was known about the mechanisms by which perinatal HI and glutamate promote death of oligodendroglia or of the ability of trophic factors to prevent this death. Previous in vitro studies suggested that maximal survival of OPs under normal culture conditions could be achieved using a combination of the IGF, neurotrophin and interleukin-6 (IL-6)-like families [Barres et al., 1993]. Several of these factors have been further tested for their ability to protect oligodendroglia against damaging or toxic agents. IGF-1 and CNTF (a member of the IL- 6 type cytokines) protect immature oligodendrocytes from death induced by tumor necrosis factor- $\alpha$ [Louis et al., 1993; D'Souza et al., 1996; Ye and D'Ercole, 1999]. Prior to our studies, there was one report suggesting that NT-3 partially inhibited glutamate excitotoxicity of oligodendroglia [Kavanaugh et al., 2000]. Our studies demonstrated that IGF-1 and NT-3, but not CNTF, protect late OP cells from high levels of glutamate through $24 \mathrm{~h}$ in vitro [Ness and Wood, 2002]. However, only IGF-1 protects the late OP cells from glutamate toxicity longer than $24 \mathrm{~h}$ [Ness and Wood, 2002]. More recently, we determined that IGF-1 blocks glutamate-mediated death in the late OPs by preventing Bax translocation, mitochondrial cytochrome $\mathrm{c}$ release and cleavage of caspases 9 and 3 [Ness et al., 2004]. However, IGF-1 has no effect on initial calcium influx into the late OPs after exposure to glutamate nor does it promote recovery of intracellular calcium levels [Ness et al., 2004] as has been reported for IGF1 trophic actions in neurons [Cheng and Mattson, 1991, 1992, 1994; Cheng et al., 1993; Mattson and Cheng, 1993; Mattson et al., 1993].

There are limited data concerning the ability of IGF-1 to prevent white matter damage and OP death in vivo following HI in the immature brain. Recently, Lin et al. [2005] demonstrated that IGF-1 given prior to the insult partially rescues OPs and myelin basic protein (MBP) expression following bilateral $\mathrm{HI}$ in the perinatal rat brain. However, there is no information as to the effectiveness of IGF-1 to rescue white matter OPs if given after the insult. The goal of the studies presented here was to further understand the timing and mechanisms for IGF-1 protection and rescue of the late OPs from insult both in vitro and in vivo.

\section{Materials and Methods}

Minimal essential media (MEM), fetal bovine serum (FBS), and trypsin were purchased from Gibco/Invitrogen (Carlsbad, Calif., USA). Cell culture supplements and glutamate were purchased from Sigma Chemical Company (St. Louis, Mo., USA). Recombinant rat IGF-1 was purchased from Upstate Biochemicals (Lake Placid, N.Y., USA). Recombinant human fibroblast growth factor2 (FGF-2) was purchased from R\&D Systems (Minneapolis, Minn., USA). Rabbit polyclonal antibodies to activated caspase 3 and Olig 2 were obtained from Cell Signaling Technologies (No. 9661; Danvers, Mass., USA) and Chemicon International (Temecula, Calif., USA), respectively. Antibodies to MBP and to $\beta$-actin were obtained from Chemicon International (rat monoclonal to MBP a.a. 82-87) and from Sigma-Aldrich Corp. (mouse monoclonal; St. Louis, Mo., USA), respectively. Goat anti-rabbit and mouse horseradish peroxidase-conjugated secondary antibodies were purchased from Jackson Laboratories (West Grove, Pa., USA).

\section{Cell Culture and Treatment Conditions}

Newborn Sprague Dawley rat forebrain cortices were enzymatically digested with trypsin and DNase I and then mechanically dissociated and plated in MEM containing 10\% FBS with antibiotics as previously described [Levison and McCarthy, 1991]. The mixed glial cells were grown in T75 flasks until they were confluent (10-14 days). Microglia were separated from the cultures by shaking the flasks on a rotary shaker for $1.5 \mathrm{~h}$ at $260 \mathrm{rpm}$. OP cells were isolated following an additional 18-hour shake as previously described [McCarthy and de Vellis, 1980]. OP cells were seeded into poly-D-lysine-coated T75 flasks at a density of $1.5 \times 10^{4} / \mathrm{cm}^{2}$ in a chemically defined medium, N2S, composed of: (1) $66 \%$ N2B2 media [DMEM:F12 (Gibco, Grand Island, N.Y., USA; containing $15 \mathrm{mM}$ HEPES, $2 \mathrm{mM}$ glutamine) supplemented with $0.66 \mathrm{mg} / \mathrm{ml} \mathrm{BSA}, 10 \mathrm{ng} / \mathrm{ml}$ d-biotin, $5 \mu \mathrm{g} / \mathrm{ml}$ insulin, $20 \mathrm{nM}$ progesterone, $100 \mu \mathrm{M}$ putrescine, $5 \mathrm{ng} / \mathrm{ml}$ selenium, $50 \mu \mathrm{g} / \mathrm{ml}$ apo-transferrin, $100 \mathrm{U} / \mathrm{ml}$ penicillin, and $100 \mu \mathrm{g} / \mathrm{ml}$ streptomycin], (2) 34\% B104-conditioned medium (N2B2 preconditioned 
by B104 neuroblastoma cells), (3) $5 \mathrm{ng} / \mathrm{ml} \mathrm{FGF-2,} \mathrm{and} \mathrm{(4)} 0.5 \%$ FBS. OP cultures were amplified for 4-10 days and passaged once using papain [Young and Levison, 1997] prior to performing experiments. The lineage stages of oligodendrocyte differentiation have been extensively characterized in vitro using stage-specific monoclonal antibodies as markers [Ranscht et al., 1982; Bansal et al., 1989; Bansal and Pfeiffer, 1992, 1997; McMorris and McKinnon, 1996; Orentas and Miller, 1999; Baumann and Pham-Dinh, 2001]. The early OP is bipolar, mitotic and can be identified by expression of glanglioside antigens (detected by immunostaining with either A2B5 or R24 antibodies). Using these isolation procedures, we consistently obtain greater than $95 \%$ purity of early OP cells (A2B5+/O4-) as previously reported [Jiang et al., 2001].

As the early OP begins to differentiate, it progresses through an intermediate progenitor stage that is still mitotic but multipolar. Late OPs can be identified by the surface antigen POA (detected by immunostaining with the $\mathrm{O} 4$ antibody). Under differentiation conditions, the late OP differentiates into a postmitotic immature oligodendrocyte that can be identified by immunostaining for galactocerebroside (GalC, detected by the $\mathrm{O} 1$ or Ranscht antibodies). Ultimately, the immature oligodendrocyte will further mature into a fully differentiated oligodendrocyte characterized by production of myelin proteins including MBP and proteolipid protein. To obtain highly enriched cultures of late OPs for experiments, early OP cells were replated at a density of $4.0 \times 10^{4}$ cells $/ \mathrm{cm}^{2}$ onto poly-D-lysine-coated $60-\mathrm{mm}$ dishes in N2B2 with $0.5 \%$ FBS and $10 \mathrm{ng} / \mathrm{ml} \mathrm{FGF}-2$ for $48 \mathrm{~h}$. Under these conditions, we obtain cultures that contain $90-95 \% \mathrm{O}^{+}$late OPs, 6-8\% R24+/O4- OPs, $1-2 \%$ Ranscht $^{+}$immature OLs, $<2 \%$ GFAP+ astrocytes and $<0.01 \%$ OX $42^{+}$microglia [Ness and Wood, 2002]. For glutamate and trophic factor treatments, a hormone-supplemented medium was used that was identical to the N2B2 medium with the absence of insulin. Treatment media did not contain FGF-2. Cells were treated for various time points with $500 \mu \mathrm{M}$ glutamate and/or IGF-1 (10 $\mathrm{ng} / \mathrm{ml}$ ), and media were replaced every $18 \mathrm{~h}$.

\section{Western Blotting}

Following treatments, OP cells were washed in ice-cold PBS and total cell lysates were isolated in SDS sample buffer $(62.5 \mathrm{mM}$ Tris- $\mathrm{HCl}, 2 \%$ SDS, $10 \%$ glycerol, $50 \mathrm{~mm}$ DTT, 1/100 protease inhibitor cocktail (Sigma), $1 \mathrm{mM} \mathrm{Na}_{3} \mathrm{VO}_{4}$, and $1 \mathrm{~mm} \mathrm{NaF}$ ) and sonicated for $10-15 \mathrm{~s}$ on ice. Protein assays were performed to determine protein concentrations (BioRad, Hercules, Calif., USA). 15$25 \mu \mathrm{g}$ of protein was heated to $100^{\circ} \mathrm{C}$ for $5 \mathrm{~min}$, cooled, and separated on 10,12 or $3-8 \%$ mini-SDS polyacrylamide gels (Invitrogen). Proteins were then electrotransferred to nitrocellulose membranes. Membrane blocking and primary and secondary antibody incubations were done in 5\% milk (or 5\% BSA for some antibodies) in TBS $0.05 \%$ (or $0.1 \%$ ) Tween-20. Protein was visualized using an enhanced chemiluminescence system (New England Nuclear, Boston, Mass., USA) following incubation with appropriate horseradish peroxidase-conjugated secondary antibodies. Images were digitized and quantified using NIH Image 1.62.

\section{HI Model and Olig2 Immunocytochemistry}

The left common carotid artery of PND7 outbred Wistar rats was ligated under anesthesia. Following recovery, the pups were exposed to $60 \mathrm{~min}$ of hypoxia in a humidified chamber at $36^{\circ} \mathrm{C}$ with $7.77 \pm 0.01 \%$ oxygen in nitrogen. Immediately after $\mathrm{HI}$, pups were treated with human recombinant IGF-1 (50 $\mu$ g; Genentech,
Inc.) or vehicle $(\mathrm{NaCl} 0.9 \mathrm{mg} / \mathrm{ml})$ i.c.v. and then this dose was repeated once daily for 2 days as described previously [Brywe et al., 2005]. The dose of IGF-1 was chosen based on our previous studies in 7-day-old rats where this dose showed neuroprotection [Brywe et al., 2005] and on similar studies in adult rats [Guan, 1993] where this dose showed the most significant neuroprotection without affecting systemic glucose concentrations or cortical temperature. The injection procedure was well tolerated by the pups and there was no mortality. Animals were perfused at PND10 and the brains removed from the skull and immersion-fixed at $4^{\circ} \mathrm{C}$ for $24 \mathrm{~h}$, dehydrated and embedded in paraffin.

Coronal brain sections $(5 \mu \mathrm{m})$ were cut from paraffin blocks, deparaffinized and dehydrated through a graded series of xylenes and ethanol. For analysis of Olig2 expression, sections were analyzed at Bregma -0.3 to -0.9 from all brains. After incubation in proteinase K (10 $\mu \mathrm{g} / \mathrm{ml}$; Sigma) in $10 \mathrm{~mm}$ Tris, $\mathrm{pH} 8.0$ for $15 \mathrm{~min}$, antigen retrieval was performed in $10 \mathrm{mM}$ sodium citrate buffer using the pressure cooker method. Sections were incubated with a rabbit polyclonal antibody to Olig $2(1: 100)$ overnight at $4^{\circ} \mathrm{C}$ followed by incubation with a goat anti-rabbit IgG alkaline phosphatase (1:250; Southern Biotech, Birmingham, Ala., USA). Immunoreactivity was detected with VectorRed Alkaline Phosphatase Substrate Kit I (Vector Laboratories, Burlingame, Calif., USA) solution for $30 \mathrm{~min}$ at room temperature in the dark. Sections were incubated with $4^{\prime}, 6^{\prime}$-diamidino-2-phenylindole (1:2,500; Sigma) for $4 \mathrm{~min}$ at room temperature in the dark to detect nuclei. Sections were then dehydrated, and mounted in CytosealXYL (Richard-Allan Scientific, Kalamazoo, Mich., USA).

\section{Quantification and Statistical Analyses}

Photomicrographic images were captured by an individual blinded to the experimental conditions using a Sensys camera mounted on an Olympus Provis AX70 microscope at $40 \times$ magnification. DAPI and rhodamine images were captured on each of three, adjacent fields along the white matter tracts (lateral to the subventricular zone) on both left and right hemispheres of sections from IGF-1- $(n=6)$ or saline-treated $(n=6)$ animals. Cell counts were performed using a grid overlay. Differences between treatment groups were determined by Student's t test.

\section{Results}

\section{Transient Exposure to Glutamate Results in Delayed Death of Late OPs}

Our previous studies demonstrated that exposing late OPs to glutamate in the absence of either IGF-1 or insulin induced cell death beginning at 22-24 $\mathrm{h}$ [Ness and Wood, 2002; Ness et al., 2004]. Glutamate-mediated death of the late OPs is initiated by calcium influx through AMPA/ kainate receptors; however, Bax translocation to the mitochondria was not evident until at least $20 \mathrm{~h}$ following glutamate treatment [Ness et al., 2004]. It was not clear from these studies whether continuous exposure to glutamate is required to kill the late OPs. Since we do not use a glutamate receptor desensitizing blocker, we predicted 

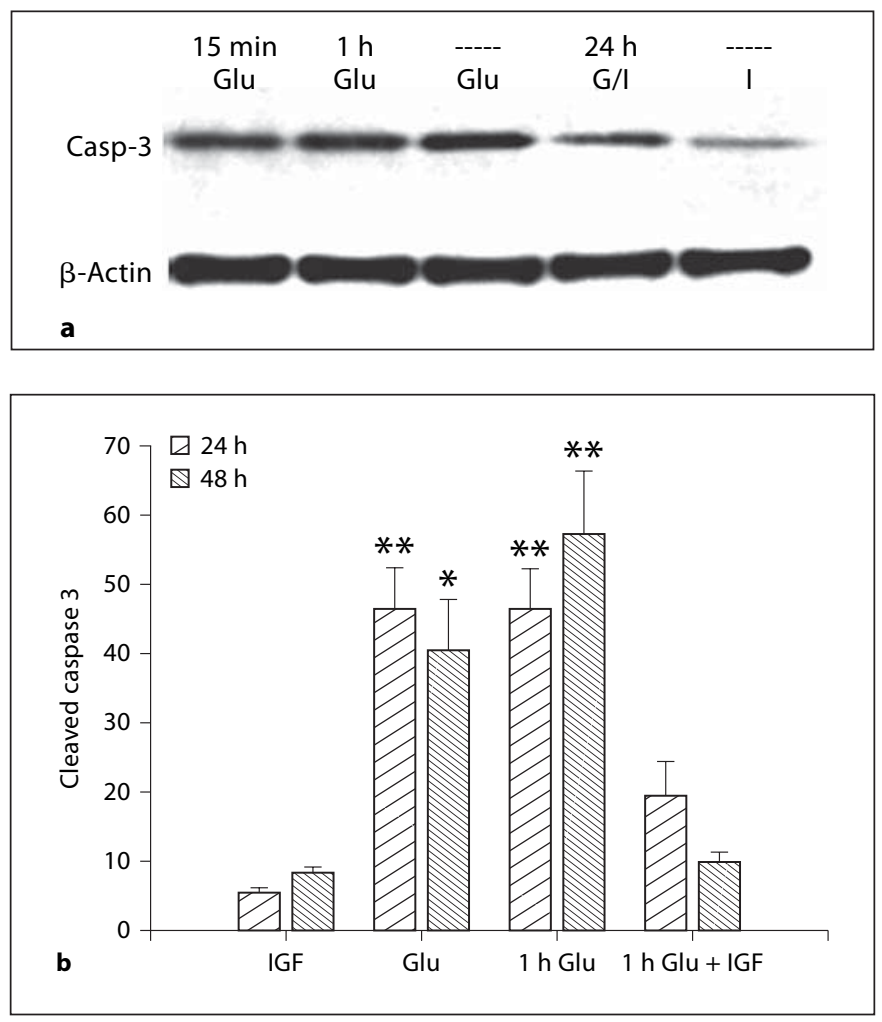

Fig. 1. Transient ( $\leq 1$-hour) exposure to glutamate is sufficient to activate caspase 3. Primary cultures of late OPs were exposed to IGF-1 $(10 \mathrm{ng} / \mathrm{ml})$, or glutamate $(500 \mu \mathrm{M})$ for $24 \mathrm{~h}(\mathrm{Glu})$ or to glutamate for $15 \mathrm{~min}$ or $1 \mathrm{~h}$ only and then switched either to control media (1 h Glu) or to media containing IGF-1 (1 h Glu + IGF) for an additional $23 \mathrm{~h}$. Levels of cleaved caspase 3 were analyzed by Western immunoblotting at 24 and 48 h. a Representative Western immunoblot showing cleaved caspase 3 and $\beta$-actin on the same blot. b Band intensities were quantified using NIH image and normalized to levels of $\beta$-actin. ${ }^{* *} \mathrm{p}<0.001$ vs. IGF- 1 or $1 \mathrm{~h}$ Glu + IGF-1; * $\mathrm{p}<0.04$ vs. IGF-1 or 1 h Glu + IGF-1.

that continuous glutamate exposure is not required for death of the cells. In order to determine whether a transient exposure to glutamate is sufficient to kill the late OPs, we tested whether $\leq 1 \mathrm{~h}$ exposure to glutamate is sufficient to induce apoptosis at $24 \mathrm{~h}$. In these experiments, we used cultures enriched for the $\mathrm{O}^{+} / \mathrm{GalC}^{-}$stage of the late OP. The late OPs were exposed to $500 \mu \mathrm{M}$ glutamate for 1 or $24 \mathrm{~h}$ and then the media were replaced with glutamate-free media. Levels of active caspase 3 were determined by Western immunoblotting at 24 and $48 \mathrm{~h}$ (fig. 1). Confirming our hypothesis, 1-hour exposure to glutamate was sufficient to activate caspase 3 in the late OPs, and this short exposure was as effective as continuous exposure to glutamate for $24 \mathrm{~h}$. Adding IGF-1 to the medium immediately after stimulating the cells with glutamate almost completely attenuated caspase 3 activation at both $24 \mathrm{~h}$ and $48 \mathrm{~h}$ of recovery (fig. 1b). Exposure to glutamate for $15 \mathrm{~min}$ similarly activated caspase 3 at $24 \mathrm{~h}$ (fig. 1a). These data suggest that a transient exposure to glutamate causes the delayed death of OPs in the absence of a receptor densensitizing agent and of IGF-1R signaling (due to either IGF-1 or micromolar levels of insulin). These results suggest that the initial calcium influx from glutamate exposure initiates a cascade of intracellular events leading to cell death.

\section{Late Addition of IGF-1 Can Prevent \\ Glutamate-Mediated OP Death}

The delayed death of the OPs following exposure to glutamate suggests the possibility of interfering with the death cascade during the 24-hour time period prior to caspase activation. To determine whether delayed addition of IGF-1 could prevent glutamate-mediated apoptosis of the late OPs, we performed experiments where the late OPs were exposed to glutamate for 12 or $16 \mathrm{~h}$ prior to addition of IGF-1 (fig. 2). After this initial period of glutamate exposure, cells were maintained in medium containing either IGF-1 alone or glutamate plus IGF-1. Strikingly, adding IGF-1 almost completely attenuated the cleavage of caspase 3 at both 12 and $16 \mathrm{~h}$ after glutamate exposure (fig. 2).

\section{Late Addition of IGF-1 after Glutamate Exposure \\ Promotes Oligodendrocyte Differentiation}

While inhibiting caspase 3 activation correlates well with cell survival in the short term, there are noncaspasemediated cell death cascades that might still be initiated by glutamate that would compromise the survival and differentiation of OP cells. To determine whether IGF-1 can completely enhance OP cell viability, we tested whether exposure to glutamate followed by recovery in medium that would stimulate the IGF-1R would allow the late OPs to survive and then to differentiate. Late OP cells were exposed to $18 \mathrm{~h}$ of glutamate in the absence of IGF-1 or insulin and then transferred to medium containing glutamate and/or IGF-1. After $12 \mathrm{~h}$, cells were transferred to differentiation media for 3 days (that contained supraphysiological levels of insulin and thyroid hormone). Differentiation into immature oligodendrocytes was subsequently determined using morphological criteria and the expression of MBP. Cells exposed to glutamate and deprived of IGF-1R stimulation had weak expression of MBP compared to control cells, whereas cells exposed to IGF-1 $18 \mathrm{~h}$ after exposure to glutamate expressed levels of 


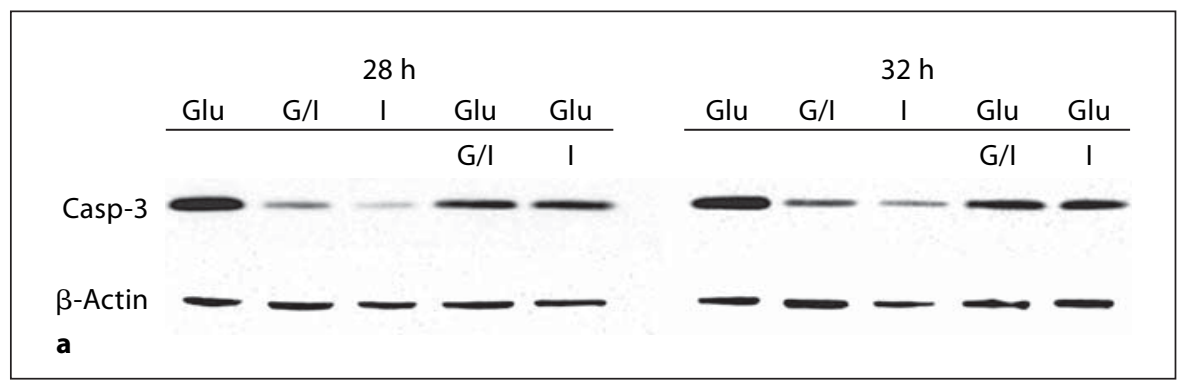

Fig. 2. IGF-1 can rescue late OPs after 12or 16-hour exposure to glutamate. Primary late OPs were treated with IGF-1, glutamate or glutamate + IGF-1 for the times indicated above the immunoblots (a) or along the $\mathrm{x}$-axis (b). Isolated protein was analyzed for cleaved caspase 3 by Western immunoblotting and normalized to $\beta$-actin as for the previous figure. Some cells were treated for 12 or $16 \mathrm{~h}$ with glutamate and then switched to media containing either IGF-1 (I) or Glu + IGF-1 (G/I) for 8, 12 or $16 \mathrm{~h}$ as indicated. a Representative Western immunoblots showing cleaved caspase 3 and $\beta$-actin from the same blots from the 28- or 32-hour experiments. b Quantification of active caspase 3 after normalization to $\beta$-actin. Total treatment times are indicated on the $\mathrm{x}$-axis and coded as $24 \mathrm{~h}$ (light gray bars), $28 \mathrm{~h}$ (dark gray bars), and $32 \mathrm{~h}$ (black bars).

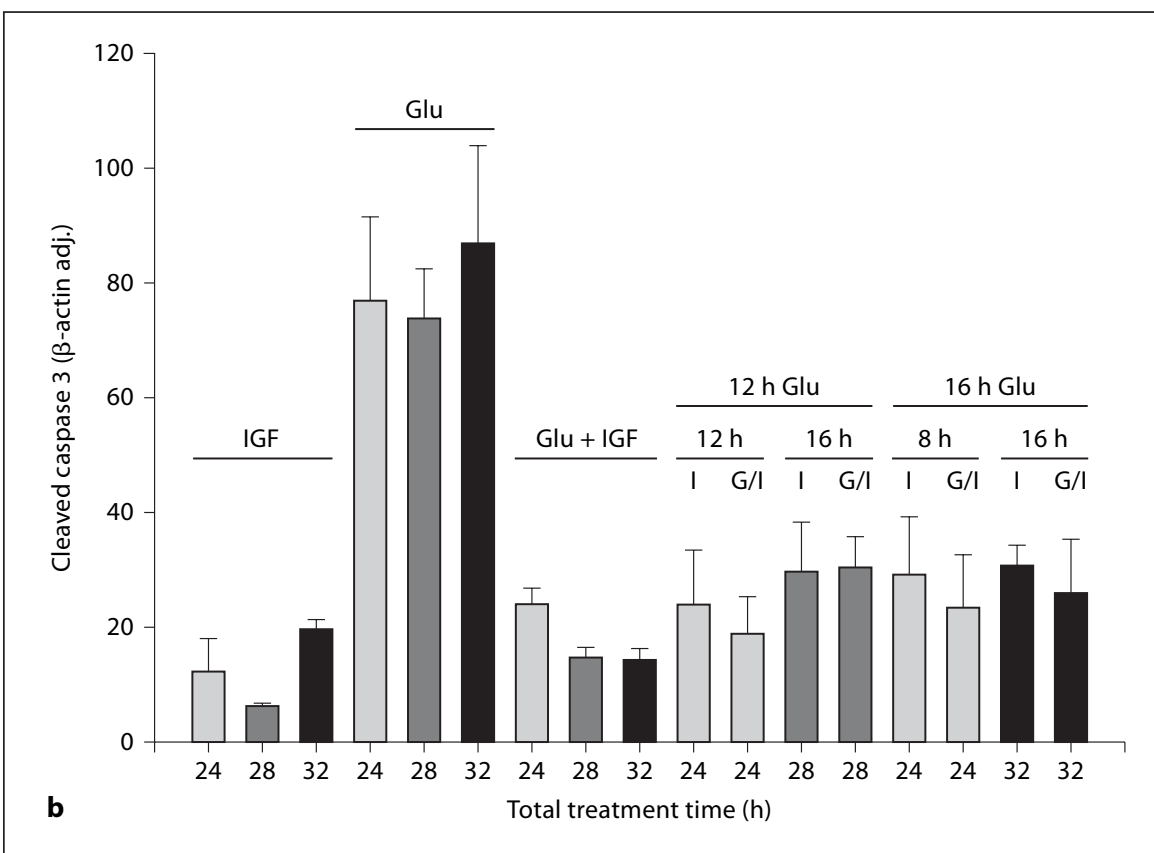

MBP that were higher than the glutamate only-stimulated group, and which were almost equivalent to cells in complete medium that were not exposed to glutamate (fig. 3). Analysis of MBP levels from duplicates of the 30hour experiment shown in figure 3 showed that MBP levels in the glutamate only treatment were $50-60 \%$ of those in the group treated for $18 \mathrm{~h}$ with glutamate and then switched to IGF-1-containing media for $12 \mathrm{~h}$ prior to differentiation. An additional experiment performed through $36 \mathrm{~h}$ with $24 \mathrm{~h}$ glutamate plus $12 \mathrm{~h}$ of IGF-1 showed similar results: MBP protein levels in the glutamate alone condition were $30-40 \%$ of MBP levels in the conditions switched to IGF-containing media. Interestingly, while there was significant death of cells in the cultures exposed to glutamate alone for $30 \mathrm{~h}$ until the differentiation treatment, the remaining cells did go on to express MBP; however, at levels lower than levels in the IGF-1 rescue conditions. Our results suggest that the ex- posure to glutamate does not irreversibly alter OP viability or their capacity to differentiate if they are subsequently stimulated with IGF-1 or high insulin-containing media. Moreover, these cells can go on to produce myelin proteins. These results support the hypothesis that the cascade of events initiated by glutamate-induced calcium influx is reversible within a few hours prior to Bax translocation and cytochrome c release.

\section{IGF-1 Administration after HI in the Perinatal Brain Retains Normal OP Numbers}

The in vitro studies described above demonstrate that IGF-1 can rescue OPs subsequent to glutamate exposure. While numerous studies have investigated neuronal death and protection following $\mathrm{HI}$ in the perinatal brain, few studies have evaluated the vulnerability and rescue of immature oligodendroglia after HI. To test whether addition of IGF-1 after HI can rescue oligodendroglia in 


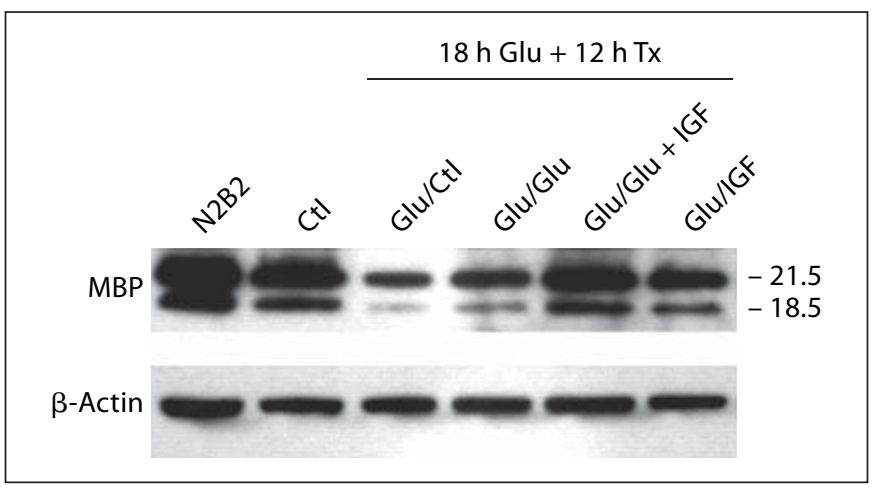

Fig. 3. Late addition of IGF-1 to OPs after glutamate exposure rescues myelin protein expression following differentiation. Primary late OPs were treated for $30 \mathrm{~h}$ with full media containing high insulin (N2B2), control media without insulin (Ctl). Additional cultures were treated with glutamate for $18 \mathrm{~h}$ followed by an additional $12 \mathrm{~h}$ in glutamate alone (Glu/Glu), glutamate plus IGF-1 $(\mathrm{Glu} / \mathrm{Glu}+\mathrm{IGF})$ or IGF-1 alone (Glu/IGF). After the $30 \mathrm{~h}$ of treatment, all cultures were switched to differentiation media for $72 \mathrm{~h}$. Isolated protein was analyzed for expression of $\mathrm{MBP}$ or $\beta$-actin by Western immunoblotting. Blot is representative of 3 independent experiments with each condition per experiment analyzed in duplicate.

vivo, we analyzed PND10 rat brains $72 \mathrm{~h}$ following HI. Differentiation of oligodendrocytes begins between PNDs 10-14 in rats; thus, the oligodendroglia at PND 7-10 are predominantly late OPs. Olig2 is a transcription factor whose expression identifies cells of the oligodendroglia lineage. Therefore, we quantified the number of Olig2 ${ }^{+}$cells in the ipsilateral white matter following administration of either IGF-1 $(50 \mu \mathrm{g})$ or saline i.c.v. after HI. A prior analysis of damage and neuronal protection by IGF-1 in these brains revealed that IGF-1 reduced neuronal damage by $40 \%$ overall with significant neuroprotection observed in the cortex, hippocampus, and striatum [Brywe et al., 2005]. We analyzed sections from these same brains to evaluate the extent to which IGF-1 could protect the white matter and resident immature oligodendroglia (fig. 4). Cell counts performed by an investigator blinded to the conditions revealed that the total number of cells in the white matter was reduced to $78 \%$ in the HI vs. contralateral hemisphere (fig. $4 \mathrm{a}, \mathrm{b}, \mathrm{e} ; \mathrm{p}=$ $0.02)$. The number of Olig $2^{+}$cells in white matter of the ipsilateral hemisphere was reduced to $65 \%$ of the contralateral hemisphere (fig. $4 a, b, e ; p=0.04$ ). Administration of IGF- 1 completely rescued the loss of Olig $2^{+}$cells in white matter (fig. $4 \mathrm{c}-\mathrm{e} ; \mathrm{p}=0.04$ ). Interestingly, while there was a trend towards rescue of total white matter cells with IGF-1 administration, this did not reach statistical significance suggesting that IGF-1 preferentially rescued the Olig $2^{+}$cell population (fig. $4 \mathrm{e}$ ).

\section{Discussion}

In previous studies, we demonstrated that death of late OPs from glutamate in vitro involves Bax translocation and a mitochondrial apoptotic pathway that occurs 20-24 $\mathrm{h}$ following exposure to glutamate. Here, we demonstrate that 1-hour exposure to glutamate is sufficient to initiate death of the late OPs in the same time frame. Moreover, we found that IGF-1 interferes with the glutamate-induced death pathway in the late OPs when administration is delayed as much as $16-18 \mathrm{~h}$ following glutamate exposure. Moreover, these cells can proceed to differentiate and to produce myelin proteins, suggesting that the cells are not irreversibly committed to die until near the time when Bax translocation occurs. We also demonstrate that, when administered following the insult, IGF-1 protects white matter OPs from $\mathrm{HI}$ in vivo in the perinatal brain.

Multiple investigators have used cell culture paradigms to characterize the molecular mechanisms of glutamate toxicity on oligodendrocyte lineage cells. There are significant differences in the approaches taken in these in vitro investigations and, thus, in the results obtained and conclusions drawn. The major differences that are critical for interpreting the data and generalizing to the in vivo conditions are the stage of cells utilized, the method for glutamate treatment and the culture conditions. Of note is that the majority of the in vitro systems used to study glutamate toxicity in the oligodendroglial lineage have used cells that are positive for galactocerebroside $\left(\mathrm{GalC}^{+}\right)$, a marker for postmitotic immature or mature oligodendrocytes [Yoshioka et al., 1995; Matute et al., 1997; McDonald et al., 1998a; Sanchez-Gomez and Matute 1999; Alberdi et al., 2002; Sanchez-Gomez et al., 2003]. As discussed previously, increasing evidence suggests that the most vulnerable stage of the lineage in rodent, sheep and human white matter is the $\mathrm{O}^{+} / \mathrm{GalC}^{-}$late OP. Thus, we developed a culture system to enrich for the late OP cell [Ness and Wood, 2002]. Under conditions that promote progression to the late OP stage but prevent further differentiation, we generate cultures that are greater than $90-95 \% \mathrm{O}^{+}$late OPs with only $1-2 \% \mathrm{GalC}^{+}$cells (detected by O1 or Ranscht antibodies), $6-8 \%$ early progenitors ( $\left.\mathrm{A} 2 \mathrm{~B} 5^{+} / \mathrm{O}^{-}\right),<2 \%$ astrocytes, and $<0.01 \%$ microglia [Ness and Wood, 2002].

A second distinguishing difference between our in vitro system vs. other paradigms is the absence of the recep- 


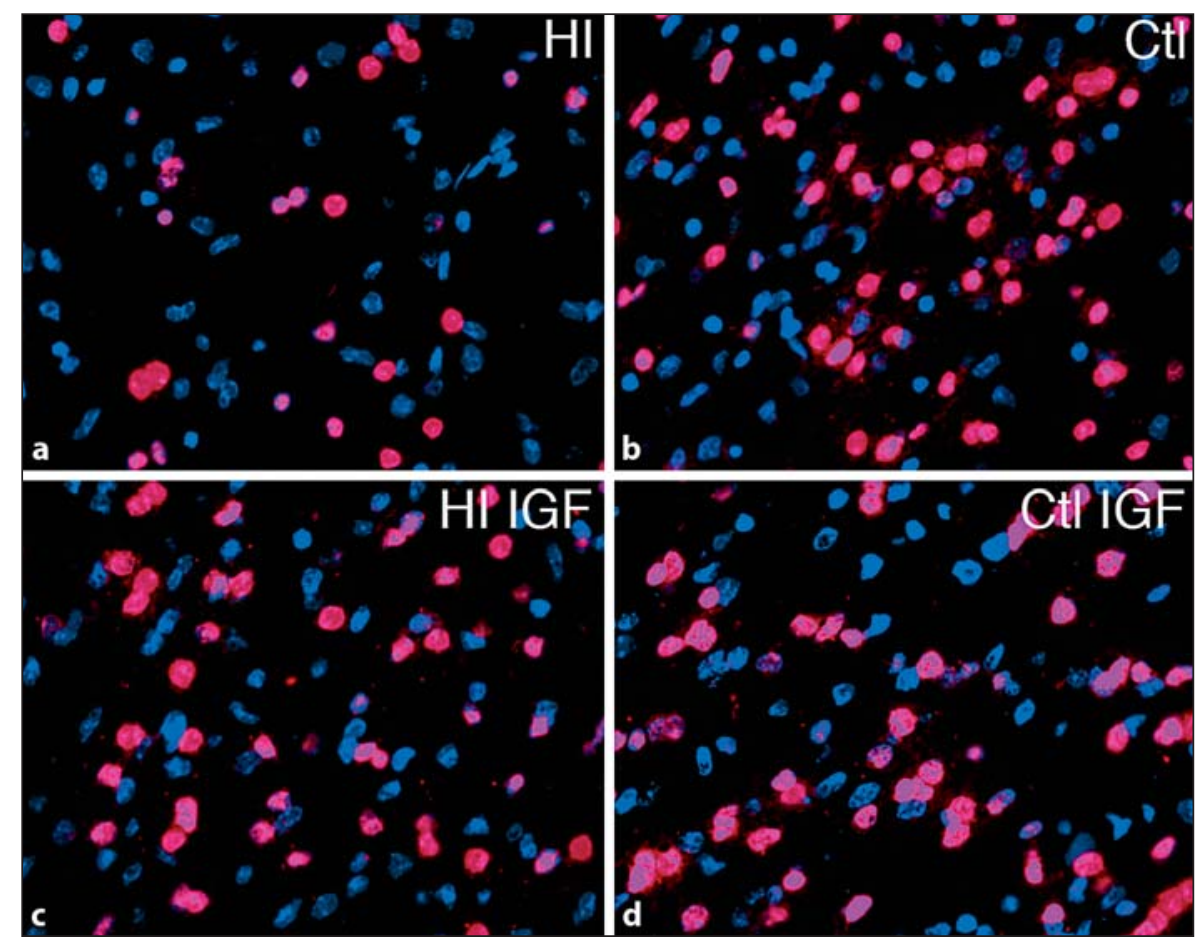

Fig. 4. IGF-1 administration after $\mathrm{HI}$ in the perinatal brain prevents loss of Olig $2^{+}$cells in white matter. a-d Olig2 immunostaining in corpus callosum from PND10 rat brains $72 \mathrm{~h}$ after exposure to $\mathrm{HI}(\mathbf{a}, \mathbf{c})$ or hypoxia alone $(\mathbf{b}, \mathbf{d})$ and treatment with either IGF-1 (c, d) or saline $(\mathbf{a}, \mathbf{b})$. DAPI (blue) was used to detect all nuclei. Double-positive cells appear as pink since the Olig2 ${ }^{+}$transcription factor is present in the nucleus. e Graph showing average number of total DAPI + cells or Olig $2^{+}$cells per field (average of 3 fields per hemisphere, $\mathrm{n}=6$ for each condition). ${ }^{*} \mathrm{p}=0.02$ vs. Ctl for DAPI counts and $\mathrm{p}=0.04 \mathrm{vs}$. Ctl for Olig2 counts; ${ }^{* *} \mathrm{p}=0.04$ vs. HI.

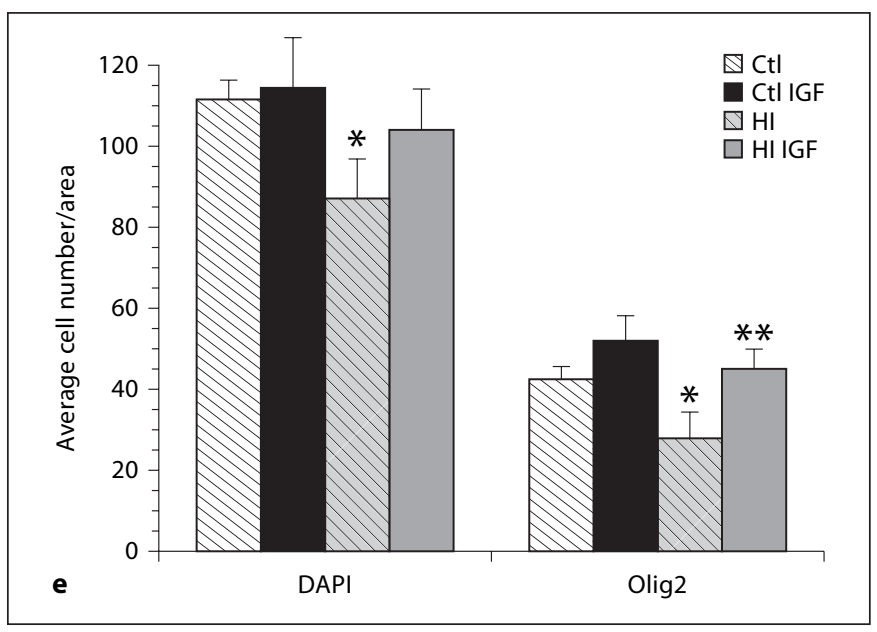

tor-desensitizing blocker, cyclothiazide, which inhibits desensitization at AMPA-preferring receptors [Yoshioka et al., 1995; Matute et al., 1997; Matute, 1998; McDonald et al., 1998a; Sanchez-Gomez and Matute, 1999; Li and Stys, 2000; Alberdi et al., 2002; Sanchez-Gomez et al., 2003]. In addition, other laboratories use culture media containing micromolar levels of insulin, which activate the IGF-1R. In contrast, the insulin levels in our system are absent or physiological (nanomolar range), which do not activate the IGF-1R. This modification to the culture medium formulation is critical since our previous studies demonstrated that stimulating the IGF-1R antagonizes glutamate-stimulated OP death through sustained activation of Akt and downstream survival pathways [Ness and Wood, 2002]. The required addition of AMPA receptor-desensitizing agents used in other studies to obtain significant glial cell death is likely a direct consequence of including high insulin in the media as well as to using the postprogenitor stage of immature oligodendrocytes. Without the AMPA-R desensitizing blocker, we observe death of the late OPs after 20-24 h, a time frame consistent with the peak of active caspase 3 in the perinatal $\mathrm{HI}$ brain and with the incidence of ISEL ${ }^{+}$cells in the white matter in the p7 rat brain after HI [Han and Holtzman, 
2000; Ness et al., 2001]. HI in the perinatal rat brain also reduces expression of IGF-1 within the first $24 \mathrm{~h}$ [Lee et al., 1996]. Taken together, the absence of a desensitizing blocker and reduced IGF-1R signaling as employed in our in vitro studies are likely to better model the in vivo state of the white matter after perinatal HI.

A critical finding of these studies is that administering IGF-1 following HI completely rescues loss of OPs in the white matter of the neonatal rat brain. Moreover, our data suggest that IGF-1 preferentially rescues oligodendroglia vs. other white matter glia after $\mathrm{HI}$ in the immature brain. A recent study demonstrated that IGF-1 partially rescued $\mathrm{O}^{+}$late OPs and MBP expression following bilateral $\mathrm{HI}$ in the perinatal rat brain [Lin et al., 2005]. However, in this study, IGF-1 was administered as a single dose prior to the $\mathrm{HI}$ insult, which may account for the partial rescue of OPs in this study. Consistent with our results, postinsult administration of IGF-1 following bilateral artery occlusion in the near-term sheep prevented loss of proteolipid protein-positive cells in the white matter [Cao et al., 2003]. While IGF-1 is a poor mitogen for OPs in vitro, our previous studies demonstrate that it significantly enhances OP proliferation induced by mitogens such as FGF-2 and PDGF [Jiang et al., 2001; Frederick and Wood 2004]. HI in the immature brain results in proliferation of stem/pro- genitor populations [Back et al., 2002; Felling et al., 2006; Yang and Levison, 2006]. Thus, it is possible that rescue of the OP cells in our study was due in part to an increase in proliferation of the OPs that was augmented by infusion of IGF-1. However, our previous studies demonstrated that excitotoxic death of late OPs in vitro occurs over a protracted time course [Ness and Wood, 2002] similar to the time course observed for death of OPs following $\mathrm{HI}$ in vivo in the neonatal rat brain [Ness et al., 2001]. Moreover, the in vitro results presented here suggest that IGF-1 treatment is effective in blocking excitotoxic death when administered just prior to the time when we observe initiation of mitochondrial-mediated apoptosis in the late OPs [Ness et al., 2004]. Thus, the results of these studies contribute to the viewpoint that administering IGF-1 will prevent white matter damage and promote myelination in the immature brain even if given several hours after insult.

\section{Acknowledgements}

The authors thank Bill Tyler for technical advice and helpful comments. This work was supported by Public Health Service grants from the National Institute of Neurological Disorders and Stroke, NS37560 and NS50742 awarded to T.L.W.

\section{References}

Alberdi E, Sanchez-Gomez M, Marino A, Matute C (2002): $\mathrm{Ca}^{2+}$ influx through AMPA or kainate receptors alone is sufficient to initiate excitotoxicity in cultured oligodendrocytes. Neurobiol Dis 9:234-243.

-Andine P, Sandberg M, Bagenholm R, Lehmann A, Hagberg H (1991): Intra- and extracellular changes of amino acids in the cerebral cortex of the neonatal rat during hypoxic-ischemia. Brain Res Dev Brain Res 64:115-120.

Back SA, Craig A, Kayton RJ, Luo NL, Meshul CK, Allcock N, Fern R (2007): Hypoxia-ischemia preferentially triggers glutamate depletion from oligodendroglia and axons in perinatal cerebral white matter. J Cereb Blood Flow Metab 27:334-347.

Back S, Gan X, Li Y, Rosenberg P, Volpe J (1998): Maturation-dependant vulnerability of oligodendrocytes to oxidative stress-induced death caused by glutathione depletion. J Neurosci 18:6241-6253.

Back SA, Han BH, Luo NL, Chricton CA, Xanthoudakis S, Tam J, Arvin KL, Holtzman DM (2002): Selective vulnerability of late oligodendrocyte progenitors to hypoxia-ischemia. J Neurosci 22:455-463.
Back SA, Luo NL, Borenstein NS, Levine JM, Volpe J, Kinney HC (2001): Late oligodendrocyte progenitors coincide with the developmental window of vulnerability for human perinatal white matter injury. JNeurosci 21:1302-1312.

Bansal R, Pfeiffer S (1992): Novel stages in the oligodendrocyte lineage defined by reactivity of progenitors with $\mathrm{R}-\mathrm{mAb}$ prior to $\mathrm{O} 1$ galactocerebroside. J Neurosci Res 32:309316.

Bansal R, Pfeiffer SE (1997): Regulation of oligodendrocyte differentiation by fibroblast growth factors. Adv Exp Med Biol 429:6977.

-Bansal R, Warrington A, Gard A, Ranscht B, Pfeiffer S (1989): Multiple and novel specificities of monoclonal antibodies $\mathrm{O} 1, \mathrm{O} 4$, and R$\mathrm{mAB}$ used in the analysis of oligodendrocyte development. J Neurosci Res 24:548-557.

- Barres B, Schmid R, Sendtner M, Raff M (1993): Multiple extracellular signals are required for long-term oligodendrocyte survival. Development 118:283-295.

Baumann N, Pham-Dinh D (2001): Biology of oligodendrocyte and myelin in the mammalian central nervous system. Physiol Rev 81: 871-927.
Benveniste H, Drejer J, Schousboe A, Diemer NH (1984): Elevation of the extracellular concentrations of glutamate and aspartate in rat hippocampus during transient cerebral ischemia monitored by intracerebral microdialysis. J Neurochem 43:1369-1374.

Brywe KG, Mallard C, Gustavsson M, Hedtjarn M, Leverin AL, Wang X, Blomgren K, Isgaard J, Hagberg H (2005): IGF-I neuroprotection in the immature brain after hypoxiaischemia, involvement of Akt and GSK3beta? Eur J Neurosci 21:1489-1502.

Cao Y, Gunn AJ, Bennet L, Wu D, George S, Gluckman PD, Shao XM, Guan J (2003): Insulin-like growth factor (IGF)-1 suppresses oligodendrocyte caspase-3 activation and increases glial proliferation after ischemia in near-term fetal sheep. J Cereb Blood Flow Metab 23:739-747.

Cheng B, Mattson MP (1991): NGF and bFGF protect rat hippocampal and human cortical neurons against hypoglycemic damage by stabilizing calcium homeostasis. Neuron 7: 1031-1041.

Cheng B, Mattson MP (1992): IGF-I and IGF-II protect cultured hippocampal and septal neurons against calcium-mediated hypoglycemic damage. J Neurosci 12:1558-1566. 
Cheng B, Mattson MP (1994): NT-3 and BDNF protect CNS neurons against metabolic/excitotoxic insults. Brain Res 640:56-67.

-Cheng B, McMahon DG, Mattson MP (1993): Modulation of calcium current, intracellular calcium levels and cell survival by glucose deprivation and growth factors in hippocampal neurons. Brain Res 607:275-285.

D'Souza S, Alinauskas K, Antel J (1996): Ciliary neurotrophic factor selectively protects human oligodendrocytes from tumor necrosis factor-mediated injury. J Neurosci Res 43: 289-298.

-Felling RJ, Snyder MJ, Romanko MJ, Rothstein RP, Ziegler AN, Yang Z, Givogri MI, Bongarzone ER, Levison SW (2006): Neural stem/ progenitor cells participate in the regenerative response to perinatal hypoxia/ischemia. J Neurosci 26:4359-4369.

-Fern R, Moller T (2000): Rapid ischemic cell death in immature oligodendrocytes: a fatal glutamate release feedback loop. J Neurosci 20:34-42.

-Follett PL, Paul A, Rosenberg PA, Volpe JJ, Jensen FE (2000): NBQX attenuates excitotoxic injury in developing white matter. J Neurosci 20:9235-9241.

Frederick TJ, Wood TL (2004): IGF-I and FGF-2 coordinately enhance cyclin D1 and cyclin E-cdk2 association and activity to promote $\mathrm{G}(1)$ progression in oligodendrocyte progenitor cells. Mol Cell Neurosci 25:480492.

- Guan J, Williams C, Gunning M, Mallard C, Gluckman P (1993): The effects of IGF-I treatment after hypoxic-ischemic brain injury in adult rats. J Cereb Blood Flow Metab 13:609-616.

-Hagberg H, Andersson P, Kjellmer I, Thiringer K, Thordstein M (1987): Extracellular overflow of glutamate, aspartate, GABA and taurine in the cortex and basal ganglia of fetal lambs during hypoxia-ischemia. Neurosci Lett 78:311-317.

-Hagberg H, Thornberg E, Blennow M, Kjellmer I, Lagercrantz H, Thiringer K, Hamberger A, Sandberg M (1993): Excitatory amino acids in the cerebrospinal fluid of asphyxiated infants: relationship to hypoxic-ischemic encephalopathy. Acta Paediatr 82:925-929.

-Han BH, Holtzman DM (2000): BDNF protects the neonatal brain from hypoxic-ischemic injury in vivo via the ERK pathway. J Neurosci 20:5775-5781.

- Jiang F, Frederick TJ, Wood TL (2001): IGF-I synergizes with FGF-2 to stimulate oligodendrocyte progenitor entry into the cell cycle. Dev Biol 232:414-423.

-Kavanaugh B, Beesley J, Itoh T, Itoh A, Grinspan J, Pleasure D (2000): Neurotrophin-3 (NT-3) diminishes susceptibility of the oligodendroglial lineage to AMPA glutamate receptor-mediated excitotoxicity. J Neurosci Res 60:725-732.
Lee WH, Wang GM, Seaman LB, Vannucci SJ (1996): Coordinate IGF-I and IGFBP5 gene expression in perinatal rat brain after hypoxia-ischemia. J Cereb Blood Flow Metab 16:227-236

Levison S, McCarthy K (1991): Astroglia in culture; in Banker G, Goslin K (eds): Culturing Nerve Cells. Cambridge, MIT press, vol 1, pp 309-336.

Li S, Stys PK (2000): Mechanisms of ionotropic glutamate receptor-mediated excitotoxicity in isolated spinal cord white matter. J Neurosci 20:1190-1198.

Lin S, Fan LW, Pang Y, Rhodes PG, Mitchell HJ, Cai Z (2005): IGF-1 protects oligodendrocyte progenitor cells and improves neurological functions following cerebral hypoxiaischemia in the neonatal rat. Brain Res 1063: 15-26.

Louis JC, Magal E, Takayama S, Varon S (1993): CNTF protection of oligodendrocytes against natural and tumor necrosis factor-induced death. Science 259:689-692.

Mattson MP, Cheng B (1993): Growth factors protect neurons against excitotoxic/ischemic damage by stabilizing calcium homeostasis. Stroke 24:I136-I140; discussion I144I135.

Mattson MP, Zhang Y, Bose S (1993): Growth factors prevent mitochondrial dysfunction, loss of calcium homeostasis, and cell injury, but not ATP depletion in hippocampal neurons deprived of glucose. Exp Neurol 121:113.

Matute C (1998): Characteristics of acute and chronic kainate excitotoxic damage to the optic nerve. Proc Nat Acad Sci USA 95: 10229-10234.

-Matute C, Sanchez-Gomez M, Martinez-Millan L, Miledi R (1997): Glutamate receptor-mediated toxicity in optic nerve oligodendrocytes. Proc Nat Acad Sci USA 94:88308835.

McCarthy K, de Vellis J (1980): Preparation of separate astroglial and oligodendroglial cell cultures from rat cerebral tissue. J Cell Biol 85:890-902.

-McDonald J, Althomsons S, Hyrc K, Choi D, Goldberg M (1998a): Oligodendrocytes from forebrain are highly vulnerable to AKPA/ kainate receptor-mediated excitotoxicity. Nat Med 4:291-297.

McDonald JW, Levine JM, Qu Y (1998b): Multiple classes of the oligodendrocyte lineage are highly vulnerable to excitotoxicity. Neuroreport 9:2757-2762.

McMorris F, McKinnon R (1996): Regulation of oligodendrocyte development and CNS myelination by growth factors: prospects for therapy of demyelinating disease. Brain Pathol 6:313-329.

Ness JK, Romanko MJ, Rothstein RP, Wood TL, Levison SW (2001): Perinatal hypoxia-ischemia induces apoptotic and excitotoxic death of periventricular white matter oligodendrocyte progenitors. Dev Neurosci 23:203-208.
Ness JK, Scaduto RC Jr, Wood TL (2004): IGF-I prevents glutamate-mediated bax translocation and cytochrome $\mathrm{C}$ release in $\mathrm{O} 4+$ oligodendrocyte progenitors. Glia 46:183-194.

Ness JK, Wood TL (2002): Insulin-like growth factor I, but not neurotrophin-3, sustains Akt activation and provides long-term protection of immature oligodendrocytes from glutamate-mediated apoptosis. Mol Cell Neurosci 20:476-488.

Orentas DM, Miller RH (1999): Regulation of oligodendrocyte development. Mol Neurobiol 18:247-259.

Ranscht B, Clapshaw P, Price J, Noble M, Seifert W (1982): Development of oligodendrocytes and Schwann cells studied with a nomoclonal antibody against galactocerebroside. Proc Nat Acad Sci USA 79:2709-2713.

-Riddle A, Luo NL, Manese M, Beardsley DJ, Green L, Rorvik DA, Kelly KA, Barlow CH, Kelly JJ, Hohimer AR, Back SA (2006): Spatial heterogeneity in oligodendrocyte lineage maturation and not cerebral blood flow predicts fetal ovine periventricular white matter injury. J Neurosci 26:3045-3055.

-Sanchez-Gomez MV, Alberdi E, Ibarretxe G, Torre I, Matute C (2003): Caspase-dependent and caspase-independent oligodendrocyte death mediated by AMPA and kainate receptors. J Neurosci 23:9519-9528.

Sanchez-Gomez M, Matute C (1999): AMPA and kainate receptors each mediate excitotoxicity in oligodendroglial cultures. Neurobiol Dis 6:475-485.

Silverstein FS, Naik B, Simpson J (1991): Hypoxia-ischemia stimulates hippocampal glutamate efflux in perinatal rat brain: an in vivo microdialysis study. Pediatr Res 30:587590.

Volpe J (1997): Brain injury in the premature infant - from pathogenesis to prevention. Brain Dev 19:519-534.

Volpe J (2001a): Neurobiology of periventricular leukomalacia in the premature infant. Pediatr Res 50:553-562.

-Volpe J (2001b): Perinatal brain injury: from pathogenesis to neuroprotection. Ment Retard Dev Disabil Res Rev 7:56-64.

-Yang Z, Levison SW (2006): Hypoxia/ischemia expands the regenerative capacity of progenitors in the perinatal subventricular zone. Neuroscience 139:555-564.

Ye P, D’Ercole AJ (1999): Insulin-like growth factor I protects oligodendrocytes from tumor necrosis factor-alpha-induced injury. Endocrinology 140:3063-3072.

-Yoshioka A, Hardy M, Younkin D, Grinspan J, Stern JL, Pleasure D (1995): Alpha-amino-3hydroxy-5-methyl-4-isoxazolepropionate (AMPA) receptors mediate excitotoxicity in the oligodendroglial lineage. J Neurochem 64:2442-2448

Young G, Levison S (1997): An improved method for propagating oligodendrocyte progenitors in vitro. J Neurosci Methods 77:163168. 